The Example of Favourites; a Warning for

Sovereigns. The Memory of Aelius Sejanus and the

SPANish MONARCHY (1588-1621)

\title{
Ejemplo de privados, aviso para soberanos. La memoria de Elio Sejano en la monarquía de España (1588-1621)*
}

Roberto Quirós Rosado

Universidad Autónoma de Madrid

roberto.quiros@uam.es - https://www.orcid.org/0000-0003-1773-3254

Fecha recepción: 30.09.2019/ Fecha aceptación: 04.02.2020

\section{Resumen}

La imagen clásica de Elio Sejano, prefecto del pretorio romano y favorito del emperador Tiberio, alcanzó la Edad Moderna a través de la obra historiográfica de Cornelio Tácito. Más allá de un recuerdo aséptico, desde finales del siglo XVI se gestó en torno a su figura una doble lectura discursiva sobre los nacientes validos, su formación, la relación establecida con el príncipe, sus límites políticos y el potencial fracaso final. En el presente ensayo se analizará la genealogía de textos surgidos de autores y traductores castellanos, portugueses y

\begin{abstract}
The classical image of Aelius Sejanus, proefectus Pretorii and favourite of Tiberius Caesar, reached the Early Modern Age transmitted by the historiography of Cornelius Tacitus. Beyond an aseptic memory, in the late sixteenth century his story engendered a double reading of discourses on the rising valimientos: the education of royal favourites, their relationship with sovereigns, their political limits and their potential final failure. The present essay focuses on the textual genealogies of Castilian, Portuguese and Genoese authors or translators who took the "prodi-
\end{abstract}

* Este estudio forma parte del proyecto "FAILURE: Reversing the Genealogies of Unsuccess, 16th-19th Centuries" (H2020-MSCA-RISE, Grant agreement: 823998) dentro de las líneas de trabajo establecidas en el WP2 "Biography and the Individual. Strategy, Choise, Self-representation, Performativity”. 
Miscelánea | Ejemplo de privados, aviso para soberanos. La memoria de Elio Sejano en la monarquía de España (1588-1621)

genoveses que, con epistemologías diversas e intereses mudables, aprovecharon el «exemplo prodigioso» de Elio Sejano para articular sus propios discursos -negativos- sobre la privanza, fenómeno de poder no institucionalizado que arraigó en gran parte de las monarquías europeas en tiempos de crisis o transición.

\section{Palabras clave}

Elio Sejano; Tiberio; Tácito; tacitismo; valimiento; monarquía de España; Edad Moderna. gious example" of Aelius Sejanus to articulate their own (negative) ideas about the privanza that arose in times of crisis and transition.

\section{Keywords}

Aelius Sejanus; Tiberius; Tacitus; Tacitism; Valimiento; Monarchy of Spain; Early Modern Age 
«Uno de los medios más importantes para alcanzar la prudencia tan necesaria al príncipe en el arte de reynar es el conocimiento de las historias» Luis Cabrera de Córdoba $(1611)^{1}$

\section{Sejano,entre Tácito redescubierto y lecturas confesionales(1588-1614)}

La recuperación de las obras de Cornelio Tácito en la península Ibérica, objeto de estudio de larga perspectiva en la historiografía española, ha demostrado la relevancia de la corriente de pensamiento político derivada de tales escritos en el desarrollo de la razón de Estado austriaca $^{2}$. Las diferentes vías de introducción del historiador latino, compartidas en otros ámbitos europeos de fines del Quinientos y durante toda la primera mitad del siglo XVII, se canalizaron por pensadores y ministros para formular un postulado político que, alejado del maquiavelismo más puro, sirviese para instruir a los soberanos y ayudar a sus oficiales de

1. Así abría su primer discurso historiográfico Luis Cabrera de Córdoba en un libro, paradójicamente, dedicado a Francisco Gómez de Sandoval, duque de Lerma, en el cénit de su valimiento. L. Cabrera de Córdoba, De la Historia, para entenderla y escrivirla, Madrid, 1611, $1 \mathrm{r}$.

2. El origen del estudio sobre la recepción española de Tácito corresponde a E. Tierno Galván, "El tacitismo en las doctrinas políticas del siglo de oro español", Anales de la Universidad de Murcia, curso 1947-1948, 1948, 895-988, y el clásico ensayo de J.A. Maravall, "La corriente doctrinal del tacitismo político en España", en Maravall, J.A., Estudios de historia del pensamiento español. Siglo XVII, Madrid, 1975, 77-106. Asimismo, cabe destacar el volumen de B. Antón Martínez, El Tacitismo en el siglo XVII en España. El proceso de receptio, Valladolid, 1991; el volumen colectivo de P. Badillo O’ Farrel y M.Á. Pastor Pérez (eds.), Tácito y tacitismo en España, Barcelona, 2013; y la actualizada indagación de F. Montcher, "Autour de la raison d'État. Marché généalogique et réseaux tacitistes dans la Monarchie Hispanique”, en A. Merle y A. Ö̈ffer-Bomsel (eds.), Tacite et le tacitisme en Europe à l'époque moderne, París, 2017, 353-383. 
gobierno ${ }^{3}$. Para ello, resultaba de gran utilidad el apego de los tacitistas ibéricos al flamenco Justus Lipsius, pieza clave para comprender dicho proceso de receptio y de traducción, como demuestran las versiones de Antonio de Toledo, señor de Pozuelo de Belmonte (c. 1590), Manoel Sueiro (1613), Antonio de Herrera y Tordesillas (1615) y Baltasar Álamos de Barrientos (1594, 1614). Estos sujetos, en gran parte ministros o hechuras de cortesanos, pasaron a la lengua castellana las historias romanas y sus máximas gubernativas, los arcana Imperii que tanto habrían de influir en el conde-duque de Olivares durante su extensa privanza ${ }^{4}$.

Fue en este grupo de pensadores, cronistas y gobernantes donde se consolidase la idealización del prefecto del pretorio Elio Sejano como paradigma del mal valido, del político sin escrúpulos, del prohombre amoral que narraban los Annales de Tácito. Nacido en una familia de equites de Etruria hacia el año 20 a. C., Sejano se había servido de los lazos clientelares que le unían a diversos senadores con influencia durante el principado de Augusto para acceder a la guardia pretoriana, comandada por su progenitor, Lucio Sejo Estrabón. El ejercicio de las armas y el cuidado personal del césar le promocionaron al mando interino de este cuerpo de elite hasta que obtuvo su titularidad. El ascendiente sobre Tiberio quedó evidenciado con la pérdida de poder fáctico del Senado y la caída en desgracia de Druso, hijo del emperador que terminó asesinado por su mujer Livilla bajo los auspicios de Sejano. El prefecto del pretorio incrementó su poder en Roma con la retirada de su valedor a la isla de Capri, aunque resultó fallido su intento por desposar a la mencionada Livilla. La desmedida reacción de Sejano dio inicio a su fracaso político. A las conspiraciones contra Tiberio se sumó una violencia política sin parangón desde los tiempos de la República. Finalmente, en 31 d. C., el ambicioso prefecto alcanzó el consulado junto con su patrón y, a la par, la mano de Livilla. El ascenso de rango, de mero caballero provincial a integrarse en la dinastía Julio-Claudia, no debió colmar las altas expectativas del flamante cónsul. Su fulgurante poder, en apariencia omnímodo, gestó su propia ruina. A finales del año, el emperador ordenó un juicio sumario contra su

3. Para una visión global del fenómeno tacitista en el pensamiento europeo, el impacto político, social y cultural de las obras del historiógrafo latino, y las razones de su popularidad, vid. P. Burke, "A Survey of the Popularity of Ancient Historians, 1450-1700", History and Theory, 5/2, 1966, 135-152; P. Burke, “Tacitism, scepticism and reason of state”, en J.H. Burns (ed.), The Cambridge History of Political Thought, 1450-1700, Cambridge, 1994, 479-499; y la reciente reedición del ya clásico ensayo de A. Momigliano, "Tacitus and the Tacitist Tradition”, Ash, Rhiannon (ed.), Tacitus, Oxford, 2012, 411-434. Junto a ello, es preciso recordar el sinóptico análisis del tacitismo europeo a cargo de S. Martínez Bermejo, Translating Tacitus. The Reception of Tacitus's Works in the Vernacular Languages of Europe, $16^{\text {th }}-17^{\text {th }}$ Centuries, Pisa, 2010.

4. A. Álvarez-Ossorio Alvariño, "Las guardas reales en la corte de los Austrias y la salvaguarda de la autoridad regia”, en J. Martínez Millán y S. Fernández Conti (dirs.), La Monarquía de Felipe II: la Casa del Rey. Madrid, 2005, I, 430-453: 433. Sobre la difusión de Lipsio en el ámbito hispano, G. Corbett, “The Cult of Lipsius: A Leading Source of Early odern Spanish Statecraft”, Journal of the History of Ideas, 36, 1975, 139-152. 
antiguo privado. Sejano, su familia y allegados fueron proscritos, ejecutados y condenados a la damnatio memorio ${ }^{5}$.

Bajo el espejo histórico de Elio Sejano ofrecido por Tácito, los solicitantes de la corte de Madrid obtendrían un claro modelo negativo - un «exemplo prodigioso» ${ }^{6}$ - en el ejercicio de medrar y sobrevivir en el palacio del soberano de las Españas. Dentro de una cultura política donde se iban afianzando las múltiples herencias identitarias de la antigua Roma ${ }^{7}$, la imagen ético-política de Sejano advertía de los errores más comunes de los advenedizos y los medios para garantizarse la voluntad y el favor del príncipe. En un plano superior, el del gobierno de la Monarquía, también las enseñanzas del imperio de Tiberio permitían consolidar una voluntad universalista que, conforme envejecía Felipe II, parecía quedar abandonada por una nueva generación de ministros españoles. Si Antonio de Covarrubias afirmaba que Tácito ayudaría al «felicísimo gobierno de la monarquía de España» y a la conservación de esta, el propio Álamos de Barrientos no dudó en ofrecer su Tácito español a Francisco Gómez de Sandoval, duque de Lerma y valido de Felipe III, quien habría de restaurar en Madrid una nueva Roma capaz de sojuzgar a los pueblos, pero con la máxima suprema de proteger la religión católica ${ }^{8}$.

En este contexto ideológico de finales del Quinientos, es reseñable la escasa autonomía literaria de Sejano, bien en forma de biografía particular, bien como objeto de un análisis metódico sobre su figura. La negativa del consejo de Castilla a conceder a Baltasar Álamos de Barrientos licencia para imprimir su Suma de preceptos justos, necessarios y provechosos en Consejo de Estado, hizo que el traductor desechara sus reflexiones sobre Sejano, trasunto de Antonio Pérez. La imagen política de Sejano acabaría diluyéndose en los aforismos sobre el cortesano, eufemismo del privado: para Álamos, el valido cortesano actuaba ajeno al orden consiliar establecido, manejando por su mano tanto la administración regia como los cargos áulicos. Tales atribuciones eran observables en las obras de Tácito y su ejemplo más clarividente se hallaba en la vida de Sejano?.

5. Sobre la figura de Sejano y su contexto sociopolítico en el imperio de Tiberio, vid. D. Hennig, L. Aelius Seianus: Untersuchungen zur Refierung des Tiberius, Münich, 1975; S.J. Bingham, The Praetorian guard in the Political and Social Life of Julio-Claudian Rome, Ottawa, 1997; R. Seager, Tiberius, Oxford, 2005.

6. P. Matthieu y V. Squarciafico (trad.), Vida de Elio Seyano, Barcelona, 1621, 149.

7. P. Fernández Albaladejo, "Lecciones de Roma. Monarquía y patria común en el reinado de Felipe III", en C. Nogueira da Silva, Â. Barreto Xavier y P. Cardim (orgs.), António Manuel Hespanha. Entre a História e o Direito, Lisboa, 2015, 263-277. Una introspección histórica sobre la relevancia de los exempla de las historias grecolatinas y bíblicas en la tratadística española de los siglos XVI y XVII, en V. Pineda, "La tradición del exemplum en el discurso historiográfico y político de la España imperial”, Revista de literatura, LXVII:133, 2005, 31-48. Para una interpretación de los usos del pasado en la política europea de la Modernidad, vid. F. Benigno y N. Bazzano (eds.), Uso e reivenzione dell'antico nella politica di età moderna: secoli 16-19, Mandura, 2006.

8. Álvarez-Ossorio Alvariño, “Las guardas reales..., op. cit., 432.

9. Ch. Davis, "Baltasar Álamos de Barrientos and the nature of Spanish Tacitism", en N. Griffin et alii (eds.), Culture and Society in Habsburg Spain, Londres, 2001, 57-78: 60, 66; I.A.A. Thompson, "El valido 
Aunque el todopoderoso prefecto romano parecía ser víctima del ostracismo en que incurría directamente el mencionado Antonio Pérez, su vinculación histórica con el naciente fenómeno de los nuevos validos parecía asentarse fehacientemente en toda Europa ${ }^{10}$. En el entorno londinense del malogrado Robert Devereux, duque de Essex, y del propio secretario Pérez, el dramaturgo inglés Ben Jonson desarrolló gran parte de su carrera teatral. Tras la ejecución de su valedor, aprovechó el exemplum clásico de Sejano para estrenar una comedia trágica denominada Sejanus, his fall (1603). Esta obra, no derivada de las lecturas de Tácito sino de su reinterpretación lipsiana y fracasada en su representación, generó un erudito debate en torno a la privanza en perspectiva romana ${ }^{11}$. Fruto del interés despertado por esta figura política sería, en 1607, la aparición de otra obra, anónima, de temática julio-claudia, The tragedie of Claudius Tiberius Nero, Romes greatest Tyrant (1607), publicada por el impresor Francis Burton y dedicada al caballero Arthur Mannering ${ }^{12}$.

En la Castilla de comienzos del reinado de Felipe III, Sejano no gozaba todavía del favor de literatos y tratadistas, que primaban a los autóctonos Ruy López Dávalos y Álvaro de Luna en sus obras, pero los condicionantes del periodo iban a fomentar su vigencia política ${ }^{13}$. La racionalización de la política, según Maravall, hacía atractiva la obra de Cornelio Tácito a comienzos del siglo XVII, aunque no puede olvidarse el influjo que, en coyunturas

arbitrista: el conde-duque de Olivares y el valimiento de su tiempo", en J.A. Escudero (coord.), Los validos, Madrid, 2004, 311-322: 314.

10. La recurrencia al todopoderoso favorito de Tiberio para advertir del auge y fracaso de los validos perduraría durante más de un siglo, adaptándose su figura histórica a los diversos contextos políticos, culturales y cronológicos. J.H. Elliott, "Unas reflexiones acerca de la privanza española en el contexto europeo", Anuario de historia del derecho español, 67, 1997, 885-900; D. Amstutz, "Mécène et Séjan. Sur la figure du favori au XVIIe siècle", Dix-septième siècle, 251, 2011, 333-350; R. Quirós Rosado, "Máscara del poder, disuasión de privanzas: la imagen política de Elio Sejano en la tratadística hispánica del reinado de Carlos II", en G. Bravo y R. González Salinero (eds.), Propaganda y persuasión en el mundo romano. Actas del VIII Coloquio de AIER, Madrid, 2011, 559-579.

11. Sobre el caso específico del Sejanus, his fall y su impacto en la vida política del final del reinado isabelino y durante el periodo de Jacobo I y Carlos I, existe una abundantísima bibliografía tanto historiográfica como literaria de la obra: M. H. Wikander, "Queasy to be Touched. The World of Ben Jonson's Sejanus", The Journal of English and Germanic Philology, 78/3, 1979, 345-357; R. McDonald, "Jonsonian Comedy and the Value of Sejanus", Studies in English Literature, 1500-1900, 21/2, 1981, 287-305; A. Patterson, "Roman Cast Similitude: Ben Jonson and the English Use of Roman History", en P.A. Ramsay (ed.), Rome in the Renaissance. The City and the Myth, Binghamton, 1982, 391-394; P.J. Ayres, "Jonson, Northampton, and the Treason in Sejanus", Modern Philology, 80, 1983, 356-363; P.J. Ayres, "The Nature of Jonson's Roman History", English Literary Renaissance, 16, 1986, 166-181; B. Worden, "Ben Jonson among the Historians", en K. Sharpe y P. Lake (ed.), Culture and Politics in Early Stuart England, Stanford, 1993, 67-90. R. C. Evans, "Sejanus: Ethics and Politics in the Early Reign of James", en J. Sanders et alii (eds.), Refashioning Ben Jonson. Gender, Politics and the Jonsonian Canon, Basingtoke, 1998, 71-92.

12. The Tragedie of Claudius Tiberius Nero, Romes greatest Tyrant, Londres, 1607.

13. I.A.A. Thompson, "El valido arbitrista: el conde-duque de Olivares y el valimiento de su tiempo", en J.A. Escudero (coord.), Los validos, Madrid, 2004, 311-322: 311-313. Una completa visión sobre la panoplia de modelos históricos relativos a los privados de soberanos en la España altomoderna se encuentra en G. 
específicas, desplegaron las obras de otros autores del Principatus, caso de Tito Livio e, incluso, Séneca ${ }^{14}$. La observación de las conductas de los gobernantes julio-claudios narradas por el historiador augusteo o por Tácito no era una exclusividad para aquellos que, bajo sus obras, podían acercarse a los planteamientos de Niccolò Macchiavelli. Por ejemplo, pese a las críticas coetáneas que asimilaban Tácito con Jean Bodin y los maquiavelistas, los exempla clásicos ofrecidos en sus obras se filtrarían en autores teóricamente nada proclives a dichas tendencias. Ejemplo de ello es el tacitismo que desarrolló el doctor Eugenio de Narbona dentro de su Dotrina política civil ${ }^{15}$. Prohibida y expurgada por el Santo Oficio en fecha tan temprana como 1604, esta obra evocó una gran madurez de los conceptos relativos al valimiento, su maestría en el uso de los Annales tacitistas y una completa asimilación entre la experiencia grecorromana y la privanza de Lerma.

La presencia del autor latino se consolidó conforme se afianzaba el cambio faccional en torno al duque de Lerma, quien auspició un sistema de privanza alejado del tradicional sostenimiento de la confianza del monarca en varios favoritos ${ }^{16}$. A la par, el progresivo cambio de las directrices de la Monarquía en el marco de la Pax Hispanica ayuda a comprender el desarrollo de una rama de pensamiento político paralela al tacitismo, pero que también se vería influenciada en parte por las historias del latino ${ }^{17}$. Más allá del potencial influjo de jesuitas y franciscanos descalzos en la reorientación de las políticas de Felipe III, en contraposición a los antiguos sostenedores de la política de su progenitor (Vázquez de Arce, el conde de Chinchón y, en cierto modo, Idiáquez y el marqués de Velada), la tónica generalizada de los pensadores castellanos incidió en la defensa de la preeminencia de la monarquía de España sobre el resto de las cortes europeas y en pro de la Casa de Austria ${ }^{18}$. Un buen número de tratados confesionales del periodo se fundamentaron en conceptos tales como monarquía eclesiástica o gobierno cristiano-político, alejándose de cualquier atisbo de maquiavelismo o de desviaciones del tacitismo lipsiano hacia modelos de los políticos Bodin o Botero. No obs-

Mrozek Eliszezynski, "From the Bible to Álvaro de Luna. Historical antecedents and political models in the debate on the valimiento in Spain (1539-1625)", Mediterranea-ricerche storiche, 36, 2016, 63-78.

14. Maravall, "La corriente doctrinal del tacitismo..., op. cit. Respecto a la circulación conjunta del pensamiento senequista respecto al de Tácito, K.A. Blüher, Séneca en España. Investigaciones sobre la recepción de Séneca en España desde el siglo XII hasta el siglo XVI, Madrid, 1983, 487-506.

15. E. de Narbona, Dotrina política civil, escrita por aphorismos, sacados de la dotrina de los Sabios y exemplos de la experiencia, Madrid, 1621. Sobre la naturaleza política de la obra de Narbona, vid. Peña Echeverría, "Un breviario tacitista para gobernantes: la Doctrina política civil de Eugenio de Narbona”, en P. Badillo O’ Farrel y M.Á. Pastor Pérez (eds.), Tácito y tacitismo en España, op. cit., 269-292.

16. A. Feros, "El viejo monarca y los nuevos favoritos: los discursos sobre la privanza en el reinado de Felipe II”, Studia historica. Historia moderna, 17, 1997, 11-36. Para una panorámica historiográfica pionera sobre el valimiento en la España del siglo XVII, véase la monografía de F. Tomás y Valiente, Los validos en la Monarquía española del siglo XVII, Madrid, 1982.

17. Sobre este proceso de reajuste de las dinámicas imperiales de la monarquía de España, véase la fundamental obra de B.J. García García, La Pax Hispanica: política exterior del duque de Lerma, Lovaina, 1996.

18. J. Martínez Millán, "La transformación del paradigma "católico hispano" en el "católico romano": la Monarquía de Felipe III”, en Homenaje a don Antonio Domínguez Ortiz, Granada, 2008, II, 521-566. 
tante, al igual que en sus émulos de papel y tinta, el confesionalismo generó un fuerte debate sobre la naturaleza de los privados del rey, los límites que se debían poner a su influencia o la relación soberano-favorito a la hora de gobernar las monarquías cristianas. Sería en este punto donde la herencia clásica se dejara ver con mayor vigor, y donde Elio Sejano volviese a ser objeto de cita y reflexión.

Ya en 1588, dentro de sus Treynta libros de la Monarchía Ecclesiástica, fray Juan de Pineda dedicó varios epígrafes sobre el imperio de Tiberio para glosar la falta de moralidad y escrúpulos políticos del favorito romano: de mal consejero, envenenador, adúltero, traidor, se trata al prefecto del pretorio ${ }^{19}$. Similares epítetos le dirigió Juan de Mariana, tanto en su Historia general de España como en De rege et regis institutione, entroncando la imagen del valido con la de su correligionario Pedro de Rivadeneyra. Si para este último, Sejano era un competidor de Tiberio por su «grande poder y majestad $»^{20}$, Mariana le consideraba como un trasunto clásico de Álvaro de Luna, ya que ambos habían captado los corazones de sus soberanos, sobreponiéndose a las adversidades que les acechaban, logrando atar de tal forma sus voluntades «que apenas se podían apartar» ${ }^{21}$. El favor real no debía provenir de la amistad, sino del servicio y la eficiencia en los negocios conferidos por el soberano. El favorito solo podría acceder a un cargo representativo en el «servicio particular del príncipe», nunca al gobierno de la monarquía. La elección del privado también se ceñía al valor moral del individuo agraciado, pues si su orgullo le hacía arrogante y libre, rápidamente se ganaría el odio de los súbditos del rey, «cosa que es uno de los mayores y más temibles daños». Ejemplos de ello los encontraba el jesuita talaverano en los tiempos de Sejano, pero también «en los de nuestros padres», una evidente alusión al príncipe de Éboli y su hechura, Antonio Pérez ${ }^{22}$.

En las semblanzas jesuíticas, Sejano no era un sujeto claramente diferenciado de otros validos o favoritos de la Antigüedad, sino uno más en la larga lista que se pretendía recordar en una época en que volvían a prevalecer en el escenario político de toda la Europa occidental. No se obviaba una velada crítica de los eruditos jesuitas hacia el valimiento mediante el intencionado recurso a las ejemplares vidas de los hombres de Estado grecolatinos y bajomedievales $^{23}$. A comienzos de la década de 1610 tal era la conciencia del poder casi absoluto de los privados sobre sus monarcas que fray Juan Márquez, en su tratado El governador christiano, hacía contrastar selectas imágenes bíblicas o grecolatinas de favoritos depravados o amorales con las virtuosas vidas de Moisés y Josué, «príncipes del pueblo de Dios». Muestra evidente del ascendiente que iban teniendo en los negocios de la monarquía -en particular,

19. J. de Pineda (O. Obs.), Tabla de las materias contenidas en los Treynta libros de la Monarchía Ecclesiástica, divididos en cinco tomos, Barcelona, $1620^{2}$, s. f.

20. G. Mrozek Eliszezynski, “"Hagan los príncipes la quenta con las historias”. La carga del pasado en el debate sobre el valimiento (1598-1621)", Magallánica, Revista de Historia Moderna, 3/6, 2017, 18-38: 26.

21. J. de Mariana (S. I.), Historia general de España, compuesta primero en latín, después buelta en castellano, Madrid, 1616 3 , II, 253.

22. J. de Mariana (S. I.), De Rege et Regis institutione, libri III, Toledo, 1599, III, 3.

23. H.E. Braun, Juan de Mariana and Early Modern Spanish Political Thought, Aldershot-Burlington, 2007: 2-4. 
Lerma- y a la sempiterna lucha faccional que se desarrollaba en la corte del Rey Católico, se recoge en las siguientes palabras:

(...) si bien nunca les deven dar tanta mano, que se prometan salir con cosas injustas, como hizieron el rey Asuero con Amán, y Tiberio con Seyano, que les dieron lugar a que por medio de la privança se vengassen de los que querían mal y executassen todas las tiranías y crueldades que le venían al pensamiento: cosa tan agena de razón que por ninguna culpa merecen más aýna perderse las grandes privanças que por aprovecharse dellas los que las han alcançado para desquitar sus ofensas, como por el contrario el que desde aquel lugar sabe perdonarlas, merece durar siempre en él ${ }^{24}$.

\section{«Doctrina es esta de Tácito, con el exemplo de Seyano». La semblanza política de Elio Sejano por fray Juan de Santa María (1614)}

La intencionalidad política del recuerdo de Tiberio y Sejano, patente en el tacitismo de Álamos de Barrientos y Narbona, y entre sus impugnadores jesuitas completó su desarrollo en 1614, en un momento crítico para el valimiento del duque de Lerma, factotum de la Pax Hispanica y patrón absoluto en la corte madrileña. En dicho año, el franciscano fray Juan de Santa María dio a la imprenta su Tratado de República y policía cristiana, cuyo éxito posibilitó una rápida reimpresión ${ }^{25}$. Santa María, personaje ligado a la oposición al valido, no era un outsider desconocido para el público palatino. Su acceso a la corte de Felipe III provenía de su oficio de confesor de la infanta Margarita de Austria, si bien, tras su muerte, hubo de esperar a los cambios cortesanos de 1615-1616 para volver a reintegrarse en la primera línea cortesana al serle encargada la conciencia de Isabel de Borbón, princesa de Asturias ${ }^{26}$. Para entonces, su posicionamiento anti-sandovalista se consolidó con la difusión de su tratado, reimpreso en distintas ocasiones a finales de la década de 1610. La coyuntura temporal para la diseminación de sus enseñanzas políticas -y sus nada veladas críticas contra el privado- insertó al franciscano en las redes que trataban de alejar a Lerma de la voluntad del rey merced al púlpito de la Real Capilla y la intimidad de la confesión ${ }^{27}$. Las doctrinas políticas de Santa María, por tanto, podían articular nuevos canales críticos con el valido. La competencia de dos de los vástagos del privado,

24. J. Márquez (O. S. A.), El Governador Christiano, deducido de las vidas de Moysén y Iosué, Príncipes del Pueblo de Dios, Lisboa, $1614^{2}, 104$.

25. J. de Santa María (O. F. D.), Tratado de República, y policía christiana, para Reyes y Príncipes, y para los que en el govierno tienen sus vezes, Barcelona, $1616^{2}$.

26. S. Martínez Hernández, “Los cortesanos. Grandes y títulos frente al régimen de validos”, en J. Martínez Millán y M.A. Visceglia (dirs.), La monarquía de Felipe III: la Corte, Madrid, 2008, III, 435-581: 570.

27. B.J. García García, "Sátira política a la privanza del duque de Lerma”, en F.J. Guillamón Álvarez y J.J. Ruiz Ibáñez (eds.), Lo conflictivo y lo consensual en Castilla: sociedad y poder político, 1521-1715: homenaje a Francisco Tomás y Valiente, Murcia, 2001, 261-296: 270-271, 274, 276. 
el conde de Saldaña y el duque de Uceda, por la sucesión en el control palatino, la entrada del duque de Infantado y Baltasar de Zúñiga en el consejo de Estado, el rápido ascenso del confesor Aliaga y el lento, pero firme, acceso del conde de Olivares en la privanza del príncipe Felipe, comenzaron a hacer mella en la confianza del rey sobre su protegido ${ }^{28}$.

El tratado político de fray Juan de Santa María constituye, para Antonio Feros, «la mejor y más radical crítica a las teorías sobre los validos» que habían proliferado durante el largo decenio precedente. La claridad de la argumentación del fraile descalzo, en consonancia con los intereses de la naciente oposición cortesana a los Sandoval, articulaba un paradigma de soberano que le auguraba no solo un poder mayor que el ejercido hasta el momento por Felipe III, sino también un control efectivo sobre sus ministros y potenciales favoritos. La colaboración de la aristocracia y el sostenimiento institucional de la Monarquía sobre los consejos y secretarías -no en las juntas, mediatizadas por los privados- debían constituir los pilares de su reformación ${ }^{29}$.

En relación a los privados, validos o favoritos, las tesis doctrinales de Santa María incidieron en la sumisión de quien gozase tal favor hacia el que otorgaba la gracia: el rey. Fijando su vista en Carlos I y Felipe II, modelos de soberanos potentes y capacitados para gobernar sin caer en manos del valimiento, fray Juan expuso máximas que el privado tendría que acatar para evitar su ruina y la de su príncipe. Siguiendo a Cicerón o Ambrosio de Milán, la amistad «que no excepta casos no es amistad, sino conjuración», por lo que ésta debía basarse en la justicia y la honestidad ${ }^{30}$. La facilidad con que en los albores del siglo XVII los reyes hacían entrega de «su coraçón al privado, y le dé tanta mano que se prometa salir con cosas injustas» recordaba el tiempo en que el monarca bíblico Asuero se apoyaba en Amán, y Tiberio en Sejano. La dadivosidad de los príncipes solo lograba aumentar los deseos de venganzas personales y la puesta en práctica de «todas las tyranías y crueldades que imaginaron para desquitarse de sus ofensas» ${ }^{31}$. El temor que habían de tener los validos hacia Dios tendría tanta vigencia como su conducta personal. Para definir tal comportamiento se incluyó en el Tratado de República y policía christiana una larga semblanza sobre Elio Sejano, exemplum capaz de demostrar a los hombres de su tiempo los límites de acción del cortesano, la sensualidad y la falta de escrúpulos a la hora de gobernar un imperio:

El ser el privado modesto, afable, y mostrarse a todos, oyéndolos gratamente; es también parte de justicia, y medio muy necessario para saberlo todo, y proveer con acierto en todo: y por el contrario el hazerse dessear, es especie de sobervia, y grandeza de todos aborrecida ${ }^{32}$.

28. Martínez Hernández, "Los cortesanos..., op. cit., 435-581: 571-578; P. Williams, The great favourite. The Duke of Lerma and the court and government of Philip III of Spain, 1598-1621, Manchester, 2006, 215217.

29. A. Feros, El duque de Lerma. Realeza y privanza en la España de Felipe III, Madrid, 2002, 423-424.

30. Santa María, Tratado de República..., op. cit., 259v-260r.

31. Ibidem, 260r-v.

32. Ibidem, 262r-v. 
«Doctrina es esta de Tácito, con el exemplo de Seyano, gran privado del emperador Tiberio», decía Santa María ${ }^{33}$. Siguiendo los pasos del favorito imperial a través de las obras de Cornelio Tácito, el fraile confesor desgranaría el modus operandi del gobierno de Sejano. Apoyarse en la elite patricia ante su ascendiente social y el control de las mercedes del emperador, a la par que «nunca olvidó el trato humilde y reverencial con su príncipe, y respectivo con todos», constituyeron los pilares fundamentales para dar comienzo al ejercicio de la privanza. Sin embargo, poco duró este benévolo valimiento -que "puede ser exemplo de privados», reconocía el clérigo-, ya que ejercería un gobierno despótico basado en la ambición y la codicia, lo que convertía a Sejano en «aviso de reyes» ${ }^{34}$. El alejamiento del emperador, retirado a Capri, coadyuvó a que el favorito se hiciese con las riendas del poder. Su praxis gubernativa, administrativa y no consiliar, parecía tener tintes de actualidad:

finalmente [Sejano] lo vino a mandar todo con no dar audiencia a nadie, reduziéndolos a que hablassen y negociassen por escrito para que assí nada se tratasse, ni resolviesse sin que él lo supiesse; y dezía que reduziendo los negocios a cartas y papeles, se respondía con más acuerdo y consideración que de palabra: artificio con que se apoderó de todo, y lo que más es del coraçón del príncipe ${ }^{35}$.

Las palabras de fray Juan de Santa María tenían un símil en su tiempo: la concesión por Felipe III al duque de Lerma de plenos poderes para ser obedecido por los consejos supremos de la Monarquía en 1612. El tenor de la cédula real oficializaba la dependencia de las instituciones sinodiales hacia la figura naciente del valido universal, cuyas altas atribuciones políticas le distinguían de los antiguos privados regios a la usanza del siglo pasado ${ }^{36}$. Las semejanzas entre los poderes de Francisco Gómez de Sandoval y Elio Sejano estaban fuera de toda duda. Así, el fraile no dudó en imprecar a Dios para que su providencia alejase el peligro que este nuevo fenómeno político acechaba a España y su monarca:

(...) líbrenos Dios de hombres ambiciosos, interesales, y codiciosos, que todo su cuydado es hazer en su particular allegar para sí, y para los suyos, y todo su fin para conservarse en la gracia de los reyes, hazer con ellos lo que la hormiga con el grano, que para que no nazca y se pueda mejor y más tiempo aprovechar dél, le come luego el coraçón: libre Dios también a los reyes desta subjeción, e insensibilidad, y de tal calidad y condición de hombres, que lo quieren poder

33. Ibidem, 262v.

34. Ibidem, 272v.

35. Ibidem, 273r.

36. J.A. Escudero, “Los poderes de Lerma”, en J.A. Escudero (coord.), Los validos, Madrid, 2004, 122-175: 158-172; Feros, "El viejo monarca..., op. cit., 35-36; sobre la capacidad decisiva de Lerma en el gobierno político de la monarquía de Felipe III, véase el amplio ensayo de A. Alvar Ezquerra, El duque de Lerma. Corrupción y desmoralización en la España del siglo XVII, Madrid, 2010. 
y mandar todo, que los unos no se pueden escapar de tormenta, y los otros corren mucho riesgo de anegarse en ella ${ }^{37}$.

Aunque el efecto directo de la crítica de Santa María pudo atenuarse por la intervención del duque de Lerma en contra de la obra, los ataques hacia el valido se siguieron sucediendo durante el resto de su privanza ${ }^{38}$. El mismo tenor de las acusaciones del fraile franciscano se observa en las alusiones de Francisco de Quevedo en su Política de Dios (compuesta en 1617) y de Pedro Martínez Navarrete en dos pasajes de su famoso arbitrio Conservación de Monarquías y discursos políticos (c. 1619-1620, pero no publicado hasta 1626) ${ }^{39}$. Por su parte, en Del rey y de la razón de gobernar (1616), Mateo López Bravo llegaría más allá que sus coetáneos, afirmando sin ambages cómo los privados tendían a persuadir al soberano para que abandonase sus deberes regios en su provecho personal. Como acaeció en el valimiento de Sejano con Tiberio, dicha dejación de obligaciones y el ocultamiento del príncipe por parte de su favorito podrían provocar el colapso del gobierno filipino y, por ende, de la Monarquía ${ }^{40}$.

\section{1: el triunfo de un valido fracasado: Elio Sejano, de Pierre Matthieu a Vincenzo Squarciafico}

La muerte de Felipe III en 31 de marzo de 1621 dio inicio al periodo más fructífero para el devenir de la historia madrileña de Sejano. La subida al trono de Felipe IV trajo consigo la consolidación del duunvirato Baltasar de Zúñiga-Gaspar de Guzmán frente a la privanza de duque de Uceda y el confesor Aliaga ${ }^{41}$. Estas mutaciones provocaron la aparición de tratados y opúsculos con una temática inequívocamente formativa sobre un nuevo modelo de valimiento, opuesto al ejercido durante más de dos décadas por los Sandoval.

Tres obras ligadas a la corriente tacitista de la razón de Estado serían las que recurrieron al ejemplo clásico de Elio Sejano para dotar de reglas de conducta a los favoritos del nuevo monarca: la definitiva impresión de Dotrina política civil, de Eugenio de Narbona ${ }^{42}$, la aparición de Varias noticias importantes a la humana comunicación, de Cristóbal Suárez de Figueroa ${ }^{43}$ y la traducción, parcial, de Vincenzo Squarciafico de la Vida de Elio Seyano del francés Pierre Matthieu ${ }^{44}$.

37. Santa María, Tratado de República..., op. cit., 273r-v.

38. Feros, El duque de Lerma..., op. cit., 428.

39. Mrozek Eliszezynski, “"Hagan los príncipes...”, op. cit., 28-31.

40. A. Feros, Kingship and Favoritism in the Spain of Philip III, 1598-1621, Cambridge, 2000, 238.

41. Martínez Hernández, "Los cortesanos..., op. cit., 580-581.

42. Narbona, Dotrina política civil..., op. cit.

43. C. Suárez de Figueroa, Varias noticias importantes a la humana comunicación, Madrid, 1621.

44. Matthieu/Squarciafico, Vida..., op. cit. 
La herencia de Lerma hacía conveniente una revisión del concepto de privado y de sus atribuciones de gobierno no-institucionalizado ${ }^{45}$. Pareciendo improbable, viendo la pujante facción Zúñiga-Guzmán, la vuelta a un sistema ajeno al valimiento, ciertos autores aprovecharon la coyuntura de 1621 para sacar a luz su pensamiento político. Apostaron por una nueva denominación del valido/privado/favorito como ministro superior, cuya labor no consistiría en una mera acaparación de mercedes y privilegios personales y familiares, sino en la ayuda al soberano en cuestiones palatinas o domésticas. El buen gobierno definido por el capellán del conde de Olivares, Matteo Renzi, en su Tratado del perfecto privado hizo hincapié en la actividad formativa del príncipe por parte de su favorito, a la par que este dejaba en manos de los ministros la administración del reino ${ }^{46}$. No cabe duda que tanto Renzi como el resto de plumas teñidas de 1621-1622 buscaban ganarse el favor de la facción hegemónica, pero es preciso valorar cómo el contenido de sus obras iba más allá de la mera adulación para adentrarse en un campo de debate sobre el bien de la res publica y la vigencia de la propia monarquía como cuerpo político autónomo y no mediatizado por interesados cortesanos.

Dichos elementos se observan en la mencionada Dotrina política civil de Eugenio de Narbona ${ }^{47}$. El autor había visto su obra tacitista censurada por el Santo Oficio a instancias del valido Lerma nada más ser publicada en 1604. Ahora salía de las prensas madrileñas readaptada en varios de sus epígrafes. Pese a la historia interna de la publicación, parecía convenir su publicación tanto al propio doctor Narbona como a la facción Zúñiga-Guzmán por dos factores. Por un lado, se expresaba una dura crítica contra las privanzas precedentes de los Sandoval; y, por el otro, el autor apostaba por un prototipo de gobernante con un comportamiento moral alejado del maquiavelismo, pero partícipe a su vez de un marcado realismo político de corte lipsiano ${ }^{48}$. Para ejemplificar sus tesis, regresó sobre el exemplum de Sejano. En su aforismo 186 se recurría al tercer libro de los Annales de Tácito para observar en el privado imperial una de sus facetas más aprovechables: su capacidad para el trabajo y su disimulación ante el esfuerzo de la carga del Imperio.

Si algo hiziere acertadamente el ministro, tome para sí el trabajo solo, y la gloria del sucesso déxela para el príncipe, que esto quieren todos, y aún piensan que les an devido ${ }^{49}$.

45. La resistencia cortesana al valimiento y su reflejo en escritos políticos y prácticas fiscalizadoras durante las privanzas de Lerma y Uceda se desgrana en G. Mrozek Eliszezynski, Bajo acusación: el valimiento en el reinado de Felipe III. Procesos y discursos, Madrid, 2015.

46. C. Bolaños Mejías, "Baltasar de Zúñiga, un valido en la transición”, en Escudero, J. A. (coord.): Los validos, Madrid, 2004, 243-276: 268-271; R.A. Stradling, Felipe IV y el gobierno de España, 1621-1665, Madrid, 1989, 44. Para una completa semblanza política de Baltasar de Zúñiga, véase R. González Cuerva, Baltasar de Zúñiga, una encrucijada de la Monarquía Hispana (1561-1622), Madrid, 2012.

47. J. Vilar, "Intelectuels et Noblesse: le doctor Eugenio de Narbona", Études lbériques, 3, 1968, 7-28.

48. Á.O. Álvarez, "La invención de las pasiones. Consideraciones sobre la recepción del tacitismo político en la Cultura del Barroco", Astrolabio. Revista internacional de filosofía, 10, 2010, 1-14: 11-12.

49. Narbona, Dotrina política civil..., op. cit., 64. 
Frente a la imagen de un Sejano laborioso en la dirección de los negocios públicos, serían sus facetas más oscuras las que prevalecieron en la tratadística. Modelo de ello fue el doctor Cristóbal Suárez de Figueroa, quien insertó al romano dentro de una larga serie de favoritos imperiales que, al haberse beneficiado de las grandezas emanadas de los príncipes a quienes servían, causaron la desgracia final de $\operatorname{estos}^{50}$. Perennio, Eutropio, Belisario o Artabano formaban así un mismo grupo con Sejano en la mentalidad barroca en las críticas contra el valimiento ${ }^{51}$.

El tacitismo imperante en Suárez de Figueroa o Narbona fue compartido por aquellos a quienes iban, teóricamente, dirigidas sus obras. La influencia lipsiana sobre los autores hispanos de comienzos del Seiscientos parece proverbial. Si Olivares poseía numerosos ejemplares de sus obras en su afamada biblioteca, su tío Baltasar de Zúñiga había conocido al erudito flamenco durante su legación diplomática en la corte archiducal de Bruselas y de dicho conocimiento mutuo fructificó una correspondencia epistolar. Asimismo, otro pensador político de su esfera, Juan Antonio de Vera y Figueroa, futuro conde de la Roca, había filtrado las enseñanzas tacitistas de Lipsio en el conocido tratado aristocrático-diplomático El enbaxador (Sevilla, 1620) ${ }^{52}$.

El ascenso al poder de la nueva generación de cortesanos y ministros se había producido con una relativa falta de violencia. La purga política contra la facción Sandoval, que tuvo su ejemplo más gráfico en la ejecución pública de Rodrigo Calderón, marqués de Sieteiglesias, careció de la virulencia que, solo un lustro antes, había ensangrentado las salas del Louvre parisino ${ }^{53}$. La supuesta conjura de Concino Concini, favorito de la reina Maria de’ Medici, impactó sobremanera en la opinión pública francesa hasta el punto de que los pormenores de la caída del privado italiano tomaron tintes de tragedia clásica. Solo un suceso de la Antigüedad parecía calcado a lo acaecido en el París del joven Luis XIII: el ascenso y colapso de la privanza de Elio Sejano.

La equiparación alegórica entre Concini y Sejano vino de la pluma de Pierre Matthieu ${ }^{54}$. Este erudito, políglota, había estudiado con los jesuitas, quienes despertaron su interés por la época clásica. Su formación universitaria en Valence le aupó a la elite letrada lionesa a fines de la década de 1580. Su valía y brillantez en las letras humanas le granjearon el favor de En-

50. Suárez de Figueroa, Varias noticias..., op. cit., 107.

51. Quirós Rosado, “Máscara del poder..., op. cit., 560-561.

52. B. Antón Martínez, “Tácito, ¿inspirador de la carrera política del conde-duque de Olivares?”, Minerva, 6, 1992, 285-312: 290.

53. Feros, El duque de Lerma..., 443. Sobre Rodrigo Calderón y su proceso político, vid. S. Martínez Hernández, Rodrigo Calderón. La sombra del valido. Privanza, favor y corrupción en la corte de Felipe III, Madrid, 2009.

54. M. Fumaroli, L'âge de l'éloquence. Rhétorique et res literaria de la Renaissance au seuil de l'époque classique, Ginebra, 1980, 285, n. 125. Sobre Pierre Matthieu en su contexto erudito y literario, vid. É. Tourette, Quatrains moraux XVIe-XVIIe siècles: Guy du Faur de Pibrac, Antoine Favre, Claude Guichard, Pierre Mathieu et Guillaume Colletet, Grenoble, 2008. 
rique IV y Pierre Jeannin, medianero ante el soberano, para que se le reconociera como historiógrafo real. Puesto al servicio de la naciente monarquía borbónica, abandonó rápidamente su posicionamiento ligueur para loar los éxitos del rey Enrique de Navarra y, a su vez, profundizar sobre la naturaleza del poder en una Francia en transición. Sus múltiples obras, tanto poéticas como teatrales y noveladas, fueron traducidas a los principales idiomas europeos y bien valoradas por intelectuales de la República de las Letras occidental. En el caso español, Matthieu fue leído y versionado por Lorenzo van der Hammen, Juan Pablo Mártir Rizo y Vincenzo Squarciafico, así como censurado por Quevedo, quien diría que si bien sus escritos:

tienen estimación y alabanza, [era un] hombre elocuente sin ambición, de juicio más lozano que igual, que ni disimula el amor a su patria, ni se desembaraza del aborrecimiento con los extranjeros, escribió historia grande, en partes menos legal que bien razonada ${ }^{55}$.

La publicación princeps de Aelius Sejanus. Histoire romaine, recuieillie de divers autheurs salió de la imprenta de Robert Estienne en 1617, dotada del privilegio real. El mismo año aparecieron dos ediciones en París sin contar con dicha licencia, signo de su rápido consumo por el público lector francés. Desde entonces, y hasta bien entrada la década de 1620, se sucedieron varias decenas de reimpresiones, a la par que traspasaba los límites galos para ser traducida al italiano (1619), alemán (1620), castellano (1621) e inglés (1639). El pequeño tratado biográfico contiene una intencionalidad política fuera de toda duda. Matthieu dedicó a Luis XIII el volumen mostrándole las similitudes entre el Capitolio y el Louvre, lugares donde la Fortuna fue adversa a los privados. La biografía de Sejano no solo era un revival histórico en torno al éxito y el fracaso en la convulsa Francia, sino una guía universal para cualquier príncipe donde se enseñaba cómo «deve ser muy zeloso de conservar su auctoridad», y para los nobles, a quienes advertía "qué son las privanças a quien usa mal dellas»" ${ }^{56}$ Tales eran los elementos que hacían deseables su traducción y publicación en una corte, como la española, donde en 1621 había ocurrido un marcado cambio político.

El primer traductor al castellano del Aelius Sejanus fue un financiero genovés asentado en Madrid, Vincenzo Squarciafico. Sus antepasados, que fueron señores de Chios y se hacían descender de la gens Anicia y de los Frangipane medievales, no descuidaron sus alianzas con las grandes familias del patriciado local (Giustiniani, Pallavicini, Serra, Spinola, Doria y Centurione $)^{57}$. Desde joven fue destinado a los negocios españoles de su linaje, lo que le permitió tanto desposar con una hija de negociantes ligures, Paola Gentile, como participar

55. F. de Quevedo, “Juicio a las obras de Pedro Mateo", en F. de Quevedo, Obras (edición de A. FernándezGuerra), Madrid, 1859, II, 480.

56. Matthieu/Squarciafico, Vida..., op. cit., s. p. "[Dedicatoria] Al rey de Francia”.

57. G. Squarciafico (marqués de Buscaiolo), Opúsculos del marqués de Buscayolo, de los señores y príncipes soberanos de la ciudad, e isla de Xio, cavallero de la Orden de Calatrava, y superintendente de las fortificaciones de Castilla, Valencia, 1669, 2-4; F. Gregorovius, History of the city of Rome in the Middle Ages (edición de A. Hamilton), Cambridge, 2010², 404; T. Magnusson, The urban transformation of medieval Rome, Roma, 2004, 100; E. Grendi, I Balbi: una famiglia genovese fra Spagna e Impero, Turín, 1997, 72. 
casi sin interrupción en los asientos generales durante los años 1608-1627 y en la administración de la bula de Cruzada (1608-1619/1624), en comanda con su hermano Gio Battista, lo que le convirtió en un reputado hombre de negocios ${ }^{58}$. Sin embargo, tras beneficiarse de las oportunidades bancarias durante las privanzas de Lerma, Uceda y Olivares, el impacto de la bancarrota de 1627 hundió el crédito del genovés y solo pudo recuperarse, a duras penas, con la ayuda de su hermano mayor Giuseppe Squarciafico y por facilidades en la contratación de pequeños asientos militares en Italia a comienzos de la década de $1630^{59}$.

La cercanía de Squarciafico a los círculos cortesanos de Madrid le llevó a rodearse de literatos y matemáticos españoles, italianos y portugueses. De estos contactos pudo provenir su interés por versionar el pequeño tratado político de Pierre Matthieu. La fuente en la que parece beber es la traducción italiana a cargo del incógnito Gelato Academico Humorista (Ferrara, 1619) y reimpresa en cinco ocasiones en prensas itálicas durante los años 1620 y 1621. También se desconoce el interés de Vincenzo Squarciafico por encauzar la traducción castellana de la obra, máxime con la puntualidad con que le dio a estampa el supuesto editor de la misma, el converso portugués Miguel de Silveira ${ }^{60}$. Este poeta, médico de Felipe IV y maestro de matemáticas de los difuntos monarcas Felipe III y Margarita de Austria, dedicó doblemente la obra a Giuseppe Squarciafico y a los escritores, donde a más de ponderar el valor del texto para su uso literario y político, alabó «el admirable ingenio de su traductor, tan digno de estimación, que podemos reconocerle lo que nos ha adquirido ennobleciendo con ella nuestro idioma». La modestia de Vincenzo Squarciafico habría supuesto el ocultamiento del trabajo, algo que no permitió el doctor Silveira pues eran dignas de mostrarse «a los tiempos que tanto necessitan destas memorias, para que sus documentos no permitan que queden a la posteridad semejantes historias de los que viven ${ }^{61}$.

El interés por la publicación de la semblanza de Sejano se observa en la propia aprobación del calificador inquisitorial, el jesuita Vicente Navarro:

58. C.J. de Carlos Morales, "Política y finanzas”, en J. Martínez Millán y M.A. Visceglia (dirs.), La monarquía de Felipe III: la Corte, Madrid, 2008, III, 749-865.

59. C. Álvarez Nogal, Los banqueros de Felipe IV y los metales preciosos americanos (1621-1665), Madrid, 1997, 86-87; Archivo General de Simancas [en adelante, AGS], Consejo y Juntas de Hacienda, legajo 732. Consulta del Consejo de Hacienda. Madrid, 4 de agosto de 1635.

60. J. Caro Baroja, Los judíos en la España Moderna y Contemporánea, Madrid, 1978, III, 358-359; E. Sánchez García, Imprenta y cultura en la Nápoles virreinal: los signos de la presencia española, Florencia, 2007, 12-13. Un gacetillero madrileño coetáneo le definió como sujeto insigne en las ciencias universales, pues "en él la filosofía tuvo eminencia, la medicina enseñança, la jurisprudencia decoro, la matemática consumado maestro, la latinidad eloquencia, la poética observancia, perfección y magestad”. Cfr. M. Ponce, "Relación de las fiestas que se han hecho en esta corte a la canonización de cinco santos, copiada de una carta que escrivió en 28 de junio 622”, en J. Simón Díaz (ed.), Relaciones breves de actos públicos celebrados en Madrid de 1541 a 1650, Madrid, 1982, 178.

61. Matthieu/Squarciafico, Vida..., op. cit., s. p. "A los escritores”. 
He visto la vida del romano Seyano, y me parece provechosa para cosas tocantes a govierno de príncipes, y privanças de vassallos, y otras cosas de govierno sin tener cosa en que se pueda reparar en materia de costumbres y Fe divina ${ }^{62}$.

Más elocuentes son las palabras finales con las que el traductor Squarciafico cierra su versión del original de Matthieu. Símbolo de toda una intencionalidad política por sacar a la luz un «exemplo prodigioso» de malevolencia y ambición de favoritos, señaló los arcanos para la conservación del valimiento y el servicio al príncipe:

Él quedará para siempre por exemplo prodigioso de suma maldad y ambición; y su trágico fin nos muestra, que nunca paró bien el poder mal adquirido; que no se ha de juzgar la felicidad hasta la muerte, el día hasta la noche, el edificio hasta que esté acabado. Que la privança ganada por méritos, o por ventura, se conserva con la modestia, y se pierde con la insolencia, y que la más assegurada ha de reconocer su grandeza de mano de su príncipe $e^{63}$.

El texto de Pierre Matthieu, traducido por Squarciafico y revisado por Silveira ${ }^{64}$, contiene una pléyade de aforismos que no sólo ahondan en la descripción de la naturaleza del privado, sino también constituyen un corpus de máximas para la enseñanza de príncipes. Las acciones de Sejano, retratadas no solo a partir de los textos de Tácito, sino también con referencias de Plinio, Séneca, Veleyo Patérculo, Dión Casio y Juan Zonaras, pasaron de un primer momento en que se hizo «exemplar de merecimientos para alcançar premios, y de valor para oponerse a peligros ${ }^{65}$, alcanzando un poder absoluto en Roma, disimulando ante Tiberio y ejerciendo un despotismo guiado por la ambición y los vicios. Los mecanismos del privado para sostenerse en el poder no diferían en demasía de los usos que durante las primeras décadas del siglo XVII se estaban observando tanto en la Francia borbónica como en la España austriaca. Clientelismo, venalidad, control de las guardias reales, mediatización de los cargos cortesanos y municipales eran utilizados por el favorito del césar Tiberio ${ }^{66}$. Tal era su influjo en el ánimo imperial que aquel le denominaba «compañero de sus trabajos» y le aupaba a mayores dignidades que las que por nacimiento correspondían a Sejano ${ }^{67}$. Resuenan en las palabras traducidas del historiógrafo francés las críticas a los validos sobre su supuesta amistad y similitud a los príncipes. En el caso hispano, no era un topos nuevo, pues ya fray Juan de Santa María había advertido de los peligros de la humillación del monarca de su status regio y

62. Ibidem, s. p. "Aprobación".

63. Ibidem, 149-150.

64. En relación a la traducción y las versiones autóctonas de las obras extranjeras en el Madrid de Felipe IV, así como la fortuna editorial de las obras francesas entre los lectores españoles de su tiempo, vid. F.J. Bouza Álvarez, "Necesidad, negocio y don. Usos de la traducción en la cultura del Siglo de Oro", en P. Burke y R. Po-Chia Hsia (eds.), La traducción cultural en la Europa moderna, Madrid, 2010, 269-287.

65. Matthieu/Squarciafico, Vida..., op. cit., 2.

66. Ibidem, 3, 5-6, 10.

67. Ibidem, 7.

Revista de historiografía 35, 2021, pp. 9-29 
la exaltación del favorito a la realeza ${ }^{68}$. «Esto es aniquilarse, por aventajar al criado, y destruyr su reputación, que no puede conservarse», sentenciaba La vida de Elio Seyano ${ }^{69}$.

Mediante la narración de los hechos de gobierno del prefecto del pretorio, la conducta maquiavélica del propio Tiberio y el reconocimiento de una oposición moral y política a dicha privanza por parte de los patricios romanos -velada alusión a los Grandes de España en la versión de Squarciafico- se mostraba un espejo histórico en que reflejar los sucesos contemporáneos. En ocasiones, la lectura toma un cariz œconómico. La reputación del soberano provenía de su recta dirección de los negocios de su casa y familia, máxime cuando la proyección pública de su parentela dinástica estaba intrínsecamente ligada a la vigencia política del principado. Las propias vidas de Livia, Druso, Agripina, Germánico y Nerón se habían convertido en cuestiones de Estado ${ }^{70}$. También tendrá un pequeño espacio el tópico anti-cortesano de la vida en aldea. La Roma de Tiberio y el Madrid de los Felipes constituían centros privilegiados para la búsqueda del medro personal por la vía del servicio palatino, en la concesión de mercedes y el consejo político en el organigrama senatorial (es decir, los consejos, juntas y secretarías):

Era muy difícil a los hombres de aquel tiempo resolverse a esto [el retiro] porque juzgavan, que quien lo hazía voluntariamente, se apartava de ser hombre, levantándose con los dioses, abatiéndose con los brutos. (...) La vida solitaria es más segura, la civil más peligrosa, y la rústica más agradable, y maestra de templança, diligencia, justicia y coraçón senzillo, pero no es agora tan honrosa y alegre ${ }^{71}$.

Las sentencias de Pierre Matthieu, su traductor Squarciafico y -con toda probabilidad- del editor Silveira eran propias de cortesanos duchos en la materia que comentaban. Todos lograron una posición privilegiada mediante un hábil uso de las doctrinas que Tácito, Castiglione o, más recientemente, Alonso de Barros habían enseñado a quienes deseaban escalar en el ordo socialis y la gracia de los poderosos. Las glosas tacitistas -e, incluso, senequistas- están repletas de alusiones al comportamiento honesto que habrían de compartir los cortesanos en el palacio: los grandes señores debían recompensar los servicios y honrar la virtud, «considerar la persona, y no la patria; la suficiencia y no el nacimiento». Un letrado francés de provincias, un asentista genovés y un médico judeoconverso portugués podían ver reflejadas sus carreras en las máximas que daban a la imprenta, aquéllas que advertían que «en todos tiempos ha visto Roma hombres nuevos en la cumbre de grandes honras» ${ }^{72}$.

Los méritos que el cortesano presentaba en su trayectoria áulica habrían de tener recompensa por parte del soberano. Este poseía plenas facultades para abatir a los poderosos y ascender a humildes hombres. No obstante, el favorecido por la gracia regia debía manifestar

68. Feros, El duque de Lerma..., op. cit., 424-425.

69. Matthieu/Squarciafico, Vida..., op. cit., 7.

70. Ibidem, 36-38, 51-52, 55-56.

71. Ibidem, 60-61.

72. Ibidem, 70 . 
su voluntad de alejarse de "pervertir la orden de los negocios, ni [que] el interés particular ahogue el público». Dichas conductas no harían sino conducir al rey a caer en el descrédito popular y que la población aborreciese a los privados ${ }^{73}$.

Respecto a la observación de que la cercanía del favorito al príncipe producía la retirada de este respecto a sus obligaciones de gobierno, el ejemplo de Sejano también mostraba sus efectos. La ociosidad a la que el privado rebajó a Tiberio, alejado de los negocios en Capri, conllevó la ruina del sistema político. Elio Sejano se envalentonaba con su suprema autoridad en Roma, imponiendo su criterio en materias de Estado y, a la vez, denigrando al orden senatorial al sobreponer sus hechuras sobre la elite patricia romana. Sejano, gobernador absoluto del imperio, se jactaba de ello, llegando poco a poco a humillar a su valedor y pensar en la toma del principado. Frente a ello, un párrafo de La vida de Elio Seyano sentenciaba que «El buen cortesano se contenta del provecho y dexa la honra para su señor ${ }^{74}$, mientras en otro aforismo se advertía que

Quien se halla embarcado en este mar tan peligroso [i. e.: la corte] no ha de fiarse de la bonança, sino tener siempre los ojos al cielo, para guiar a buen puerto sus esperanças ${ }^{75}$.

El manual cortesano de Matthieu y Squarciafico concluye con numerosos avisos para el favorito y el soberano. El mantenimiento de la privanza, la rápida y fortuita mudanza del éxito al fracaso y una valoración moral sobre dicho fenómeno cierran las páginas de dicha biografía romana:

El buscar demasiadas honras, y superfluydad de riquezas, no es sino levantar sobre arena una altísima torre, cuya caýda es mayor, y el precipicio de su ruyna más espantoso ${ }^{76}$.

Con tales prendas políticas, el éxito editorial de La vida de Elio Seyano no se hizo esperar. Ejemplares de la misma obra aparecían en la librería de la Torre Alta del Real Alcázar de Madrid como propiedad de Felipe IV, dentro de la serie de «Historia de personas señaladas». Otros tres volúmenes se conservaban en la rica biblioteca política de Duarte de Bragança, marqués de Frechilla y tío del duque de Bragança dom João (futuro Juan IV de Portugal). Posiblemente también fuera la Vida el ejemplar conservado en la librería del almirante de Aragón y su hermano, Pedro González de Mendoza, bailío de Lora, en 162577. Las valoraciones literarias y políticas tampoco se hicieron esperar. En el Juicio a las obras de Pedro Mateo

73. Ibidem, 71-72.

74. Ibidem, 109

75. Ibidem, 121-122.

76. Ibidem, 149.

77. F.J. Bouza Álvarez, "En la corte y en la aldea de D. Duarte de Braganza. Libros y pinturas del Marqués de Frechilla y Malagón", Peninsula. Revista de Estudos Ibéricos, 0, 2003, 261-288: 279, 281, 283, 287; F.J. Bouza Álvarez, El libro y el cetro: la biblioteca de Felipe IV en la Torre Alta del Alcázar de Madrid, Salamanca, 2005, 189, 318; T.J. Dadson, “Las bibliotecas de la nobleza: dos inventarios y un librero, año de 1625 ”, en 
(c. 1625), Francisco de Quevedo no dudó en loar tanto al autor como al traductor Squarciafico, de quien dijo que «aunque no la dio entera, ha sido sabrosa letura, haciendo mucho de su parte con nuestra malicia, leer la miseria de la felicidad ajena, a quien no han podido defender de la envidia tantos siglos», aumentando sus halagos a quien en 1625 dio la versión completa y definitiva desde el francés: su amigo personal Juan Pablo Mártir Rizo ${ }^{78}$.

\section{Epílogo}

La utilidad política de las vidas de Sejano y Tiberio consolidó una práctica intelectual que debía adecuar las imagines grecolatinas con los hombres de Estado de los siglos XVI y XVII ${ }^{79}$. En un tiempo deudor de las sombras y simulaciones que aquellos romanos personificaban, los modelos tacitistas se imponían en la mente de los gobernantes españoles, a la par que con ello se abría un debate sobre «los límites de la razón de Estado y de la disimulación honesta», basado en las experiencias del reinado de Tiberio y la privanza de Sejano ${ }^{80}$.

El influjo de dos obras disímiles, el tratado confesional de fray Juan de Santa María y la traducción de Vincenzo Squarciafico, deja entrever el creciente interés que la opinión cortesana de Madrid tenía sobre la historia clásica y sus retratos morales. La negativa imagen de Elio Sejano, conformada a través de una tradición autóctona gestada desde fines del Quinientos y de la importación de la biografía francesa de Pierre Matthieu, gestó un estereotipo político autorizado por las lecturas tacitistas que sería aprovechado durante el resto del siglo XVII. La inmediata traducción íntegra de la obra de Matthieu por Mártir Rizo - La vida del dichoso desdichado, por otro nombre el Seyano-, la inserción de Elio Sejano en una sátira novelada de Quevedo, sus ecos en los aforismos de Saavedra Fajardo, la difusión popular del romano en una comedia nueva de Juan Pérez de Montalbán con el título de El fin más desgraciado, y fortunas de Seyano, o el nada inocente título de Joseph de Pellicer para su biografía del ex-generalísimo imperial Wallenstein -El Seyano Germánico-, dan fe de ello ${ }^{81}$. Tácito, Lip-

A.G. Egido Martínez y J.E. Laplana Gil (coords.), Mecenazgo y Humanidades en tiempos de Lastanosa. Homenaje a Domingo Ynduráin, Zaragoza, 2008, 253-302: 284, 298, n. 422.

78. Quevedo, “Juicio...”, op. cit., 480. Otro juicio, con algo de desdén, recibió la versión de Squarciafico y Silveira del propio Mártir Rizo, traductor especializado en las obras de Pierre Matthieu. No obstante, sí reconoció que "es verdad que Vicencio Squarçafigo dio noticia de alguna parte breve desta historia". Cfr. P. Matthieu y J.P. Mártir Rizo (trad.), Vida del dichoso desdichado, por otro nombre el Seyano, Madrid, 1625, s. f. "Advertencia".

79. F. Rodríguez de la Flor, Pasiones frías: secreto y disimulación en el Barroco hispano, Madrid, 2005, 161.

80. Álvarez-Ossorio Alvariño, "Las guardas reales..., op. cit., 434. Sobre las censuras morales contra Tiberio por los tratadistas hispanos, vid. J.A. Fernández Santamaría, Razón de estado y política en el pensamiento español del barroco (1595-1640), Madrid, 1986, 26, 51, 56, 93, 169.

81. J. de Pellicer, El Seyano Germánico, Barcelona, 1639. Quirós Rosado, “Máscara del poder..., op. cit., 564-567. Sobre Pellicer y demás publicistas del conde-duque de Olivares, R. Kagan, "Las "plumas teñidas" de Felipe IV: ¿Periodismo o propaganda?”, en R. Chartier y C. Espejo (eds.), La aparición del periodismo en Europa. Comunicación y propaganda en el Barroco, Madrid, 2012, 87-100. 
sio, Matthieu y sus traductores se hicieron un espacio en el pensamiento y la cultura (elitista y popular) española, pues proveyeron a lectores o espectadores de elementos para ejercitar la prudencia política y reglas con las que acceder a los arcanos del arte de gobernar ${ }^{82}$.

La monarquía de España a comienzos del reinado de Felipe IV se convertiría progresivamente en un campo de experimentación práctica de la teorización tacitista. Las consecuencias no se hicieron esperar. Una década después de la aparición de las traducciones de Matthieu, el latinista francés D’Ablancourt advirtió al cardenal Richelieu de los puntos débiles del imperium del Rey Planeta, informándole de sus más firmes fundamentos políticos:

En este libro [los Annales de Tácito] se ha engendrado toda política de España e Italia; en sus doctos libros se aprende el arte de reinar, en ellos buscan consejo los príncipes de la Casa de Austria en los momentos graves ${ }^{83}$.

Los conceptos políticos tacitistas, pasados por el tamiz cristianizador de Lipsio, influyeron en la prudentia civilis que Olivares trató de desarrollar durante sus dos décadas de valimiento ${ }^{84}$. Las acciones del privado de Tiberio, narradas por el historiógrafo latino y glosadas por los autores políticos modernos, podían ser extraídas como máximas de gobierno de las que tanto gustaba el conde-duque. Así, no puede olvidarse que el Nicandro incluyera un párrafo sejanista en su infructuoso intento para defender la labor gubernativa de Gaspar de Guzmán frente a las acusaciones de sus enemigos:

Señor, en tiempo de Tiberio padecieron los amigos de Seyano, sólo a Terencio su discreción le escapó por decir miraba en el cristal o viril de Seyano a su príncipe; no tenían religión cristiana, y así se resolvieron mal, y aún después de muerto Seyano no le hallaron tan malo como pensaron. Entregósele Tiberio al pueblo sin hacer juicio en justicia, en que usó de su gentilidad y falta de religión; pero en este tiempo, donde Vuestra Majestad con su cristianísimo celo desea tanto el acierto con el bien público, y alivio de sus vasallos, consuélelos con que se vea en justicia cómo el conde [Olivares] no tiene culpa ${ }^{85}$.

Bien en el París borbónico, bien en el Madrid habsbúrgico, Elio Sejano había recobrado su existencia no entre pretorios y púrpuras senatorias. Por su trayectoria, el desdichado favorito de Tiberio permanecería en la memoria como el modelo de los límites del arte de la política.

82. Elliott, “Unas reflexiones..., op. cit., 892.

83. Cfr. Álvarez, "La invención..., op. cit., 8.

84. J.H. Elliott, Richelieu y Olivares, Barcelona, 2001, 39-40.

85. Memoriales y cartas del conde duque de Olivares (edición de J.H. Elliott, J.F. de la Peña y F. Negredo del Cerro), Madrid, 2013, I, 400. 